\title{
EL SESEO VALENCIANO DE LA COMUNIDAD DE HABLA ALICANTINA
}

\author{
Francisco Gimeno Menéndez \\ Universidad de Alicante
}

\section{INTRODUCCIÓN}

Si consideramos el lenguaje como una forma de comportamiento social, la interacción verbal es un proceso estrechamente relacionado con el contexto cultural y la función social, y el texto (o discurso) es regulado de acuerdo con normas y expectativas socialmente reconocidas. Los hechos lingüísticos deben analizarse dentro del entorno de la lengua misma y del contexto más amplio del comportamiento social.

En el estudio del lenguaje, dentro de un microcosmos socialmente determinado, el objeto de atención es el uso lingüístico en cuanto que refleja las normas del comportamiento más general. Este universo es la "comunidad (sociolingüistica) de habla", que se define como cualquier grupo humano - no necesariamente de la misma lengua - caracterizado por la interacción regular y frecuente, por medio de un sistema compartido de normas y restricciones comunicativas, y se diferencia de otros grupos semejantes por determinados comportamientos evaluati- 
vos y por una variación unidimensional organizada a lo largo de la variable sociolingüística.

En el pasado, he propuesto la posibilidad metodológica de aplicar el concepto de comunidad de habla al contexto comunicativo de las comarcas (valencianohablantes y murcianohablantes) del sur del País Valenciano, a fin de determinar aquellas comunidades menores que se caracterizan por la interacción primaria y común de sus miembros. En este caso, el repertorio lingüístico reúne las actuaciones comunicativas de esa comunidad de habla, independientemente del hecho de que se utilice la misma lengua u otra distinta. Concretamente, el repertorio lingüístico de la comunidad de habla valenciana meridional identifica la competencia sociolingüística compleja de nuestra comunidad, e integra las variedades sociales y funcionales presentes en las comarcas valencianas del sur de la frontera histórica Biar-Busot, es decir, el sociolecto valenciano y el castellano (estándar y/o murciano seseante).

1.1. Cabe recordar que las comarcas del sur del País Valenciano engloban dos (sub)regiones de habla valenciana, Xàtiva y Alacant, y una (sub)región de habla murciana, Oriola. El murciano, variedad geográfica de la lengua castellana, y particularmente su subgeolecto del sureste - conocido como murciano seseante-, aparece dentro de nuestra comunidad de habla como un sociolecto social y funcional que, por una parte, queda relegado a los grupos sociales bajos (bajo y medio-bajo) $y / 0$ al registro informal de los murcianohablantes de la (sub)región de Oriola (excluida Villena y Sax), y, por otra, se relaciona con el sociolecto castellano de los valencianohablantes de los grupos sociales inferiores de la zona sur de la frontera histórica Biar-Busot, en virtud de algunas de sus características: seseo, vulgarismos, abundantes catalanismos léxicos, etc.

El miembro de nuestra comunidad es básicamente multilectal, ya que su competencia sociolingüística trasciende su propio lecto, disponiendo de un control receptivo mayor que el productivo, y reestructura constantemente la gramática a lo largo de su vida. Los niños y adolescentes revisan de forma regular la única gramática interna de su propia lengua materna, lo cual supone una incorporación a su competencia de las variables lingüísticas - temporales, geográficas, sociales y funcionales-, aproximándose asintóticamente a una gramática multilectal (o polilectal). Con otras palabras, el hablante de nuestro contexto refleja la competencia sociolingüística interindividual de la comunidad de habla, y produce una alternancia entre los dos (sub)sistemas del repertorio, re- 
solviendo la distancia entre ellos mediante variables (v. Gimeno, 1982b; 1983a, párrafo 3.5.; 1983b).

\section{SESEO VALENCIANO}

Se define el seseo valenciano, en términos estructurales, como un fenómeno de subdiferenciación de los fonemas autónomos castellanos $\theta / \dot{s}$ (en términos binarios, oposición difusa/densa), debido a la inexistencia de dicha pareja en los sistemas primarios alicantinos - valenciano o murciano seseante - $\left(L_{1}\right)$, que implica su ausencia en el sistema secundario castellano estándar (L2). Fonéticamente, el hablante multilectal del contexto alicantino identifica dos alófonos del castellano estándar (fricativo interdental y fricativo ápico-alveolar) en el correspondiente fono fricativo ápico-alveolar catalán [’்] de sus sistemas primarios (valenciano o murciano seseante). En nuestro caso, el sistema aprendido en primer lugar (o lengua materna) es el dominante inicialmente y el primario $\left(L_{1}\right)$. Tradicionalmente, este tipo de fenómenos era descrito bajo la denominación de «sustitución de sonidos» (cfr. Jakobson, 1931, págs. 319 ss.; Weinreich, 1953, págs. 41 ss.; Weinreich, 1957, págs. 5 s.; Badia, 1964b, págs. 151 s.).

Desde el punto de vista de la sociolingüística actual, el seseo valenciano puede definirse como la adición de una regla variable a la gramática multilectal de la comunidad de habla alicantina, mostrando la estratificación socioeconómica de los hablantes y/o la diferenciación situacional o funcional. De acuerdo con ello, podemos representar dicha variable sociolingüistica de la siguiente manera:

(1)

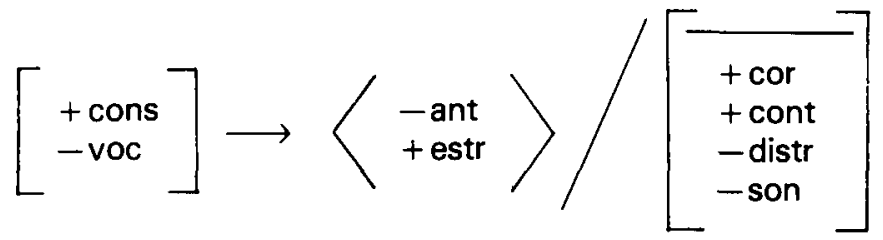

$$
p=f(\text { grupo socioeconómico) }
$$

es decir, la regla de ápico-alveolarización lo sea, las consonantes pierden su carácter anterior y se hacen estridentes, si son coronales, conti-

(1) Se trata corrientemente de una variable independiente que tiene en cuenta la profesión, el grado de instrucción y los ingresos anuales de la familia. 
nuas, sordas y no distribuidas) no se aplica siempre, sino que aparece asociada a una cantidad específica $p$, que expresa la proporción de casos en los que se aplicaría en función del grupo socioeconómico (1) de los hablantes del contexto alicantino (v. Labov, 1970; Cedergren y Sankoff, 1974; Rousseau y Sankoff, 1978; Sankoff y Labov, 1979; un resumen en Gimeno, 1979, págs. 147 ss.; López Morales, 1981).

2.1. Hav que buscar el origen del seseo apical del catalán en la desafricación de las sibilantes africadas autónomas medievales $c, c(/ \hat{\mathbf{s}} /)$ y $z(/ \hat{z} /)$ hasta convertirse en fricativas, y en su absorción por las ápicoalveolares fricativas $/ \dot{\mathbf{s}} /$ y $/ \dot{\mathbf{z}} /$. Del mismo modo, la debilitación y pérdida de la correlación de sonoridad en las africadas dorso-dentales castellanas (2), a fines de la Edad Media, son el punto de partida de la interdentalización, que refuerza la distinción entre los dos órdenes de sibilantes, y del "çeçeo-zezeo» (o generalización de las sibilantes predorsodentales $/ \$ /$ y $/ z /$ del dialecto andaluz, a costa de las ápico-alveolares $/ \dot{\mathbf{s}} /$ y $/ \dot{z} /$ ). En el siglo XVI y XVII, el término seseo consistía en la sustitución de $\zeta$ y $z$ por $/ \dot{s} /$ ápico-alveolar, y se aplicaba a la confusión del valencianohablante que utilizaba el castellano: /pláśa/, /pobréṡa/.

A este respecto, es significativo el testimonio del gramático manchego Bartolomé Ximénez Patón (1614), que distingue con criterio sociolingüístico entre las confusiones de sibilantes del andaluz y del valencianohablante:

La $c$ con cerilla [se convierte] en $s$, y la $s$ en $c$ en Español en algunas tierras por vicio de naturaleça [por defecto personal de sus lenguas] en algunas personas, y en otras por afeminarse, en otras

(2) Navarro Tomás, Espinosa y Rodríguez-Castellano (1933, pág. 272) opinan que no hay razón alguna para que la $c$ y la $z$ se pronunciasen del mismo modo en todas las regiones. Asi en catalán y valenciano la identificación de la $c$ con la $s$ supone una base común articulatoria de carácter ápico-alveolar, diferente de la que en Castilla se hizo interdental. Badia (1951, párrafo 67, II, D) no alude al punto de articulación de la sibilante africada catalana $/ \hat{s} /$, pero posteriormente (1960, pág. 2; 1964a, págs. $55 \mathrm{ss}$.) supone la misma articulación alveolar en la africada castellana y catalana. Por su parte, Alarcos (1958, págs. 34 ss.) piensa que acaso / $/$ / catalana era más ápico-alveolar que la castellana, cuya modificación iba acompañada - aunque con casi un siglo de antelación - de un paralelo ablandamiento de / $\hat{z}$ / (que hacía ya siglos había dejado de existir en catalán), y una de las causas de la confusión de $/ \vec{s} /$ y $/ \dot{\mathbf{s}} /$ catalanas pudo ser la extensión de su confluencia en inicial y en final a la posición intervocálica, que se cumplió totalmente en la primera mitad del siglo XV, aunque comenzara bastante antes. Finalmente, Galmés (1962, págs. 97 ss.) ofrece una hipótesis para sustentar que $/ \hat{\mathbf{s}} / \mathbf{y} / \hat{\mathbf{z}} /$ del catalán antiguo fueron predorsales, como el resto del íbero-románico, sin comprometer el triunfo final del seseo ápicoalveolar. 
por ser recivida en la tierra; y como que naturaleça da la tal pronunciación, aunque corrompida, pasa; como en Sevilla ordinariamente convierte la $S$ en $C$ y pienso que de vicio, diciendo $\mathrm{Ce}$ villano, ceñor, ci. En Valencia al contrario, y aquí no es vicio, sino natural pronunciación de aquel Reyno, por $c$ ponen $s$, como diciendo Mersed, Sapato, Sedaso, Alcusa, y assi a lo sevillano llamamos zezear y a lo valenciano sesear (3).

Sin embargo, el hecho de que algunos gramáticos (Arias Montano, Aldrete, Covarrubias y Dávila) equiparen el cambio sevillano y valenciano puede responder a la simple observación de la supresión de la primitiva diferencia fonológica entre sibilantes africadas y fricativas, sin reparar en el origen y carácter de la articulación propia de cada región. A partir del siglo XVIII, la significación del seseo se amplió y abarcaba, como actualmente, cualquier realización de $c$ y $z$ con una fricativa de timbre siseante, ya ápico-alveolar (valenciana), ya predorso-dental (andaluza de las clases superiores, canaria e hispanoamericana).

2.2. A raíz de las encuestas realizadas en Andalucía para la confección del Atlas Lingüístico de la Península Ibérica. (ALPI), Navarro Tomás, Espinosa y Rodríguez-Castellano (1933, págs. 258 ss.) distinguían en el murciano entre el seseo predorsal cartagenero, semejante al andaluz, y el seseo valenciano de los pueblos alicantinos de habla castellana. Los puntos de seseo en la parte sur de la provincia de Alicante, frontera lingüística del valenciano, son: Torrevieja, San Miguel de Salinas, La Bujosa (caserío), Nuestra Señora de Fuensanta (caserío), Torremendo, Nuestra Señora de los Desamparados, Montesinos, Benijófar, Rojales, Formentera, Algorfa, Almoradí, Rafal, Daya, San Fulgencio, Dolores, Catral, Albatera, Granja, Cox, Benferri, Callosa, Redován, Jacarilla, Bigastro, Benejúzar y Orihuela. Sin embargo hay distinción en el pueblo

(3) Cit. por A. Alonso (1951, pág. 68). A. Alonso (1955/1969) recogió y analizó con rigor científico la casi totalidad de los testimonios asequibles de las sibilantes, $y$, fiel a su formación de la escuela de Madrid, consideró los hechos lingüísticos en función de su contexto social y cultural. En conjunto, planteó la compleja historia de las sibilantes, examinando la pérdida de las sibilantes sonoras, la interdentalización y velarización de las sibilantes dentales y palatales, y la pugna de tendencias geográficas y sociales entre sibilantes alveolares y dentales. Posteriormente, han aparecido nuevos estudios sobre el mismo tema con datos y puntos de vista diferentes, aunque convergentes entre estos últimos, asi p. ej., Lapesa (1957; 1964), Catalán (1957a; 1957b; 1958), Menéndez Pidal (1962), Galmés (1962) y Alvar (1974). El mismo testimonio de Ximénez Patón, arriba citado, tiene, pues, dos interpretaciones (cfr. Lapesa, 1957, págs. 89 s.; Galmés, 1962, págs. 77 ss.). 
de Pilar de la Horadada. Asimismo también son seseantes Aspe y Monforte, islote lingüístico castellano en tierras valencianas. Por otra parte, observaban certeramente que en Cataluña y Valencia, donde la lengua local tampoco conoce el sonido interdental, las personas de deficiente instrucción suelen hablar el castellano empleando el sonido sibilante ápico-alveolar (pág. 225).

A. Alonso (1951, pág. 24) incorpora esos núcleos a los focos aislados actuales de seseo-ceceo, y alude lacónicamente a que pudiera tratarse de una prolongación fonética del valenciano, aunque en otra lengua. Zamora (1960, pág. 342) llega a incluir erróneamente Villena y Sax dentro de la zona seseante (v. Torreblanca, 1976, págs. 122 ss.). Y, por su parte, Lapesa (1942/1980, pág. 518) emplaza el seseo de tipo valenciano, con $/ \dot{\mathbf{s}} /$ ápico-alveolar, en Orihuela y otras localidades alicantinas de habla murciana, excepto en Villena y Sax, que conservan la distinción ente $/ \dot{s} /$ y $/ \theta /$ (casa/caza), salvo en posición implosiva (/us, has, por 'luz', 'haz', gaspacho, etc.). Y asimismo, caracteriza la peculiaridad del murciano seseante como una variedad del español actual, que presenta la persistencia de hábitos regionales, debido al bilingüismo de la zona, y que denomina "castellano de regiones bilingües» (pág. 476). .

2.3. El murciano es la variedad castellana de tránsito del extremo suroriental de la Península Ibérica, y aglutina corrientes históricas (catalanoaragonesas y mozárabes) e influencias actuales (valencianas y andaluzas). García Soriano (1932, págs. XIV-LXXVII passim) distingue seis sectores en el dialecto murciano, y sitúa el seseo valenciano en la zona del sureste, que comprende los enclaves castellanohablantes alicantinos de Elda, Monforte y Aspe, y los partidos judiciales de Orihuela y Dolores, o Vega Baja del Segura. Dicho sector aparece entrelazado a un buen número de fenómenos valencianos (fonéticos, morfológicos y léxicos), que le confieren un carácter de zona de transición entre el castellano y el catalán (valenciano). Sin embargo, nada se dice de la probable relación de continuidad de tal enclave geográfico con el bilingüismo (multilectismo) social del área Alacantí-Vinalopó, en particular, con el sociolecto castellano - murciano- de los valencianohablantes alicantinos de las clases inferiores.

Un poco más explícito es Muñoz Garrigós (1977). Geolingüísticamente, el murciano es puente entre variedades ostensiblemente diferenciadas: valenciano, andaluz y castellano. El seseo es un rasgo de influencia valenciana, y presenta un cierto grado de cohesión en el (sub)dialecto de las tierras alicantinas que hablan el castellano. Debido a una larga serie de razones que abarcan desde lo histórico a lo económi- 
co, el castellano hablado por la población bilingüe de las zonas catalanohablantes del sureste geográfico ofrece un número variable de influencias murcianas.

2.3.1. Por otra parte, Guillén (1974, págs. 22-56 passim) estudia el habla de una parte del término municipal de Orihuela, que comprende el límite del seseo. En dicha zona, la línea divisoria entre las provincias de Alicante y Murcia marca la frontera lingüística de dicho fenómeno con bastante aproximación, excepto en su partida rural de Las Norias, situada al S.O., que coincide con el murciano general. A veces, esta delimitación es tan precisa, que hay conciencia lingüística de ella, e identifica a los vecinos de la Vereda del Reino, situada al N.O., que pronuncian la sibilante interdental si viven en la parte de Castilla (Murcia), o usan habitualmente el seseo valenciano si sus casas están enclavadas en tierras del Reino (Alicante). Son núcleos de seseo, pues, las partidas rurales de La Aparecida, Arneva, Raiguero o Rincón de Bonanza, Camino de Beniel, Camino de Callosa, Correntías Altas, Correntías Bajas, Desamparados, Escorratel, Los Huertos, Hurchillo, Media Legua, Molino de la Ciudad y Molins.

En la ciudad de Orihuela, el seseo queda relegado a la clase social baja y a buena parte de la clase media, o al registro informal en las clases superiores, sobre todo en frases de carácter familiar. Una prospectiva indicativa, en este sentido, puede ser la encuesta realizada a una muestra de 240 vecinos autóctonos - según una proporcionada diversidad de sexo, cultura, profesión y condición social-, que obtuvo los siguientes resultados: seseo $\left(52^{\prime} 5 \%\right)$, distinción $\left(24^{\prime} 2 \%\right)$ y vacilación $\left(23^{\prime} 3 \%\right)$.

2.4. Nuestras investigaciones se limitan inicialmente a una encuesta sociolingüística sobre actuación, en la localidad valencianohablante de Sant Vicent del Raspeig, así como a algunos datos sobre los núcleos murcianohablantes de Asp y Elda (v. Montoya, 1981; Montoya, 1982). Entre los autóctonos de Sant Vicent del Raspeig, el seseo queda relegado mayoritariamente al grupo socioeconómico bajo $(69 \%)$, y afecta generalmente más a los hombres $(61 \%)$ que a las mujeres $(39 \%)$. En Asp el seseo es general, pero aparece la distinción entre los sectores más jóvenes, sobre todo en registros formales, debido a la indudable influencia de la enseñanza. En Elda el seseó es un fenómeno en regresión, y afecta a los estratos generacionales más maduros y a los grupos socioeconómicos inferiores. 


\section{REGRESIÓN HISTÓRICA DE LA FRONTERA LINGÜISTICA EN LA PROVINCIA DE ALICANTE}

Hasta fecha reciente el límite actual meridional del dominio lingüístico catalán ha sido mal o erróneamente conocido. Por supuesto, la evolución histórica de dicha frontera sigue siendo poco conocida, aunque es interpretada generalmente como una consecuencia de la conquista y de la repoblación subsiguiente de la zona por gentes, que hablaban ya catalán, ya aragonés (4).

Hadwiger (1905, págs. 712 s.) fue el primero que visitó las localidades limítrofes valencianas y murcianas desde Santa Pola hasta la Font de la Figuera, y señaló como límite natural el cauce del rio Vinalopó, fijando en sus riberas la isoglosa válenciana (Santa Pola, Elx, Crevillent, Novelda, el Pinós, Monóver, Petrer, Biar, el Campet, la Canyada y la Font de la Figuera) y la murciana (Asp, Montfort, Elda, Sax y Villena). De esta manera, interpretaba que la frontera actual obedecía a la penetración del castellano por el valle del río. Menéndez Pidal (1908) siguió esta delimitación y añadió algunas precisiones histórico-lingüísticas; particularménte admitió la opinión de Milá y Fontanals sobre la explicación del habla murciana de Aspe y Monforte, como efecto del origen aragonés de sus primitivos pobladores después de la conquista.

Años más tarde, Barnils (1913, págs. $7 \mathrm{~s}$.) revisa e investiga la frontera lingüística en la provincia de Alicante, señalando la conservación clarísima del catalán en Guardamar y, por consiguiente, su anexión a los pueblos limitrofes de habla valenciana. No obstante, la mejor contribución al estudio de la frontera es, sin duda, la realizada por Sanchis Guarner (1973), a través de sus primeros viajes de encuestas dialectológicas en el año 1934, para recoger los materiales del ALPI, y posteriormente en 1970. La frontera linguística dentro de la región valenciana no coincide más que parcialmente con las demarcaciones politicoadministrativas, creadas en 1833, y en cambio sigue a menudo las divisiones eclesiásticas, complicadas y realmente antiguas. Sociolingüisticamente, cabe agrupar los islotes de Elda-les Salines y la Canalosa-el Rebalso con las localidades seseantes de Asp y Montfort (v. Montoya, 1981).

(4) Cfr. Sanchis Guarner (1955/1961, págs. 103-9; 1956, págs. 180 s.). Sobre la teoría del sustrato prerromano y la frontera interna del dominio lingüistico catalán, v. Badía (1981). 
3.1. La conquista valenciana meridional representó fases terminales de las expansiones peninsulares de las dos grandes formaciones políticas hispánicas: Corona d'Aragó y Corona de Castilla. La repoblación cristiana coexistía desde un principio y se articulaba con la presencia de la antigua población musulmana. El proceso fue lento, y puede decirse que abarcaba desde el momento de la conquista hasta el siglo XVII, tras la expulsión total de los moriscos. Hay un período de mayor intensidad, siglo XIII y XIV, en el que se verificó el poblamiento de los grandes núcleos. El Regne de València fue una creación típicamente medieval, como resultado de las aspiraciones expansionistas - militar y diplomática - de la Corona d'Aragó (unión dinástica del Reino de Aragón y del Comtat de Catalunya), durante el siglo XIII y XIV (5). Prevaleció, por consiguiente, la ocupación al verdadero repoblamiento, que sólo fue efectivo en aquellos lugares conquistados por la fuerza de las armas, y, en general, la desproporción entre el conjunto cristiano y musulmán era notoria (en 1272, la población del reino se evaluaba en 30.000 cristianos y 200.000 musulmanes).

La delimitación de conquistas en el sur se estableció más de jure que de facto, entre Jaume / y el infante Alfonso $X$ en el tratado de Almirra (1244), que señalaba la frontera histórica de los reinos de València y Murcia en la línea Biar-Xixona-Busot-la Vila Joiosa (Biar, Castalla, Xixona, Relleu, Alarc, Finestrat, Torres, Polop, la Mola y Altea), quizás, en función del criterio orográfico montaña-llano (v. Llobregat, 1972, págs. 15 ss.). De este modo, la intervención de las huestes catalanoaragonesas en las revueltas de los mudéjares murcianos contra el rey castellano (1264), motivaba una política repobladora al sur de dicha línea y, sobre todo, en Elche, Alicante y Orihuela (v. Sanchis Guarner, 1960, págs. 129 ss.; Gimeno, 1971, págs. 36 ss.). Por otra parte, Jaume / ya había promulgado el Costum de València (1240), con el propósito de aplicarlo a todo el reino, el cual fue traducido del latín al catalán, e incluido en la redacción de e/s Furs de València (1261), por disposición de las primeras cortes del reino.

3.2. Posteriormente (1296-1300) y a consecuencia de la guerra con Castilla, Jaume // ocupaba todas las tierras del Reino de Murcia

(5) Sobre la hipótesis de la fundación del reino, a partir de un originario fermento antagonista de una mayoría catalana, asentados en la costa bajo una legislación proburguesa, y una minoria aragonesa. que ocuparía el interior al amparo del régimen señorial del Fuero de Aragón, v. Fuster (1962, págs. 25-28); Reglà (1968, págs. 40 ss.); Ubieto (1975, págs. 147 ss.), y Pérez Casado et al. (1980, págs. 90 ss.). 
(Alicante, Guardamar, Almoradí, Callosa de Segura, Abanilla, Orihuela, Molina, Hellín, Cieza, Ricote, Lorqui, Ceutl, Alguazas, Catral, Senorío de Crevillente, Murcia - ciudad y castillos - Caravaca, Cehegín, Mula, Librilla, Cartagena - ciudad y castillos-, y Señorío de Elche). La sentencia arbitral de Torrellas (1304) y el acuerdo de Elche (1305) estipularon la partición del primitivo reino de Murcia en dos partes, y establécian el Bajo Segura, con el término de Orihuela, como frontera divisoria meridional de la Corona d'Aragó con Castilla. La zona meridional, salvo Guardamar y Cartagena, se asignaba a Castilla, y las tierras septentrionales (ciudades de Alicante, Elche, Elda, Novelda, Orihuela y Villena) se adscribian a Aragó (v. Estal, 1982).

A excepción de Cartagena, devuelta a Castilla unas fechas después (1305), dichas tierras fueron incorporadas por Jaume // al Regne de València, bajo la denominación de REGNUM VALENTIAE ULTRA SEXONAM (o Procuracio General d'Oriola), sancionando formalmente su anexión y otorgándole la facultad de servirse de e/s Furs de Va/ència, poco después (1308). Dos siglos más tarde (1564), la bula de creación de la didcesi d'Oriola desmembraba las comarcas valencianohablantes meridionales (Baix Segura, Baix Vinalopó, l'Alacantl, les Valls del Vinalopó, Vinalopó Mitjà y A/t Vinalopól de la sede murcianohablante de Cartagena. Villena y Sax, por el contrario, permanecieron hasta nuestros días (1954) bajo esta última, ya que se relacionaron y reincorporaron más tarde al Reino de Murcia, y no pertenecieron definitivamente a la provincia de Alicante hasta la división politicoadministrativa del siglo XIX (1836), aunque dada su situación geográfica, el intercambio de población debe haber sido constante, como lo es en la actualidad (v: Senchis Guarner; 1961).

3.3. Ciertamente, ante los límites actuales meridionales del dominio lingüistico catalán, cabe hablar de una regresión histórica del valenciano en el Baix Segura (salvo Guardamar y Barba-roja - término municipal de Oriola-), les Valls del Vinalopó (sólo en el pequeño islote de la Canalosa-el Rebalso), Vinalopo Mitjà y Alt Vinalopo, que constituyen puntualmente los núcleos murcianohablantes de seseo valenciano ( $v$. fig. 1). Las causas de esta recesión, aún poco estudiadas, podían estar en la refeudalización señorial y la castellanización idiomática de las clases dirigentes del país, en el siglo XV, XVI y XVII (cfr. Ninyoles, 1972, págs. 106 ss.; v. Ferrando, 1980, págs. 93 ss.) y, en particular, a consecuencia de la represión contra el pueblo valenciano, tras el fracaso de les Germanies (1519-1522), y, sobre todo, de la expulsión de los moris$\cos (1609-1614)$ y de la peste de Oriola (1648). La subsiguiente repobla- 


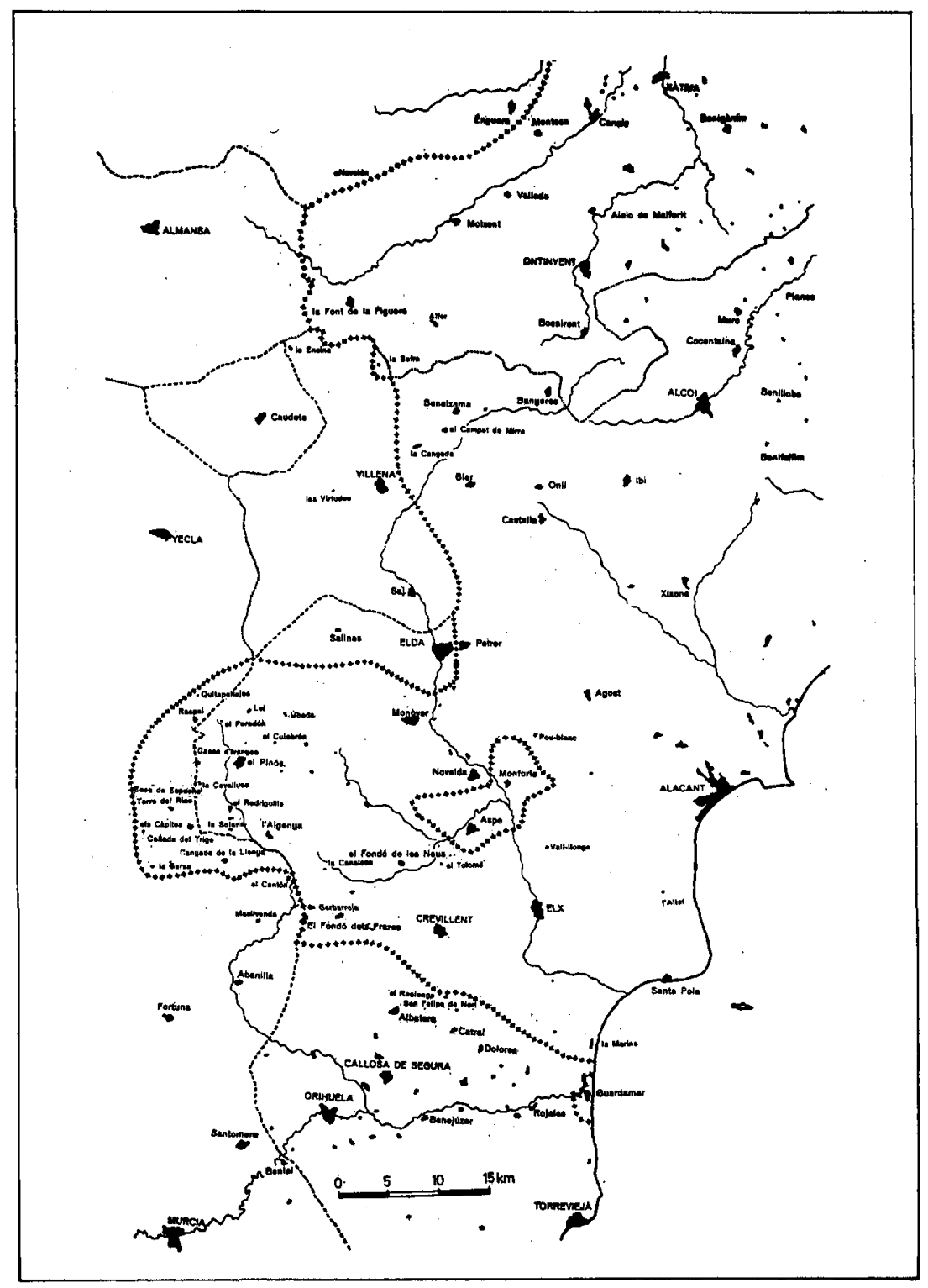

Fig. 1. Frontera lingüistica en las provincias de Alicante y Murcia. Línea de cruces: frontera lingülstica actual. Línea de trazos: frontera histórica de los reinos. Linea de puntos: limites de las provincias actuales (Sanchis Guarner, 1973, pag. 25). 
ción de los pueblos moriscos y del Baix Segura, a cargo de inmigrantes murcianohablantes de las proximidades, pudo modificar la geografía lingüística del Regne de València y explicar su actual dualidad lingüístico-territorial (v. Ventura, 1974; Millán, 1976; Sanchis Guarner, 1980, págs. 134 s.; Montoya, 1981).

Después de la victoria borbónica en la guerra de Sucesión, Felipe $V$ dictó el decreto de Nueva Planta (29 de junio de 1707), que penaba a los valencianos, partidarios del archiduque Carlos de Austria, con la abolición de els Furs de València, e implicaba la pérdida de la oficialidad de su lengua catalana, y todos sus privilegios y libertades forales, pasando a regirse por la legislación castellana. A fines de siglo, el testimonio de Cavanilles (1795/1797, págs. 266 s.) es bien explícito: en Monforte hablan un mal castellano como los de Aspe y Elda, por la inmediación a pueblos donde sólo se usa el valenciano; éste es la variedad general en todas las poblaciones del Reino de Valencia, si exceptuamos la huerta de Orihuela, y las citadas villas de Elda, Aspe y Monforte (cfr. Figueras, 1922, págs. 229 s.).

\section{REFLEXIONES FINALES: HACIA UNA HIPÓTESIS EXPLICATIVA}

He procurado examinar toda la información relativa al seseo valenciano de la comunidad de habla alicantina. A partir de ella queda suficientemente delimitado el problema que nos ocupa, y cabe caracterizarlo como uno de los casos marginales de la lingüística históricocomparativa, estructural y generativa. $Y$ por otra parte, la contribución de la dialectología $-y$ "geografía linguística» - y del funcionalismo diacrónico es escasa. Insuficiente es la explicación interna: inexistencia de la oposición fonológica autónoma castellana $\theta / \dot{s}$ en los sistemas primarios alicantinos (valenciano o murciano seseante). La explicación externa es ampliamente histórica: confusión moderna del valencianohablante que utilizaba el castellano, a partir del proceso de desafricación y apicalización de las sibilantes africadas catalanas medievales, $y$ regresión geográfico-lingüística valenciana en el siglo XVII y XVIII, desde la expulsión de los moriscos y pérdida de los privilegios forales ( $v$. Gimeno, 1984b).

Una y otra pueden ser la razón del seseo valenciano de los puntos alicantinos de habla murciana, aunque personalmente disiento de ello; ya que las preguntas fundamentales quedan sin respuesta adecuada y satisfactoria. El mismo hecho de que hasta ahora sólo se hayan abordado aspectos periféricos de esta cuestión, es todo un reto teórico y metodo- 
lógico. He esbozado en la introducción una única aproximación posible, y he estimado conveniente situarla al comienzo, para ofrecer desde entonces una posición clara: los datos lingüísticos deben analizarse dentro del entorno de la lengua misma y del contexto más amplio del comportamiento social (v. Gimeno, 1981; 1982a; 1984a; s.f.). Nuestra proposición pasa, a partir del seseo, por la determinación metodológica de la aplicación del concepto de comunidad (sociolingüística) de habla a nuestro contexto comunicativo: comarcas alicantinas del sur de la frontera histórica Biar-Busot (excluida Villena y Sax).

4.1. La comunidad de habla alicantina es multilectal, multilingüe. El repertorio lingüistico identifica la competencia compleja de nuestra comunidad, e integra las variedades sociales y funcionales presentes en las comarcas más meridionales del País Valenciano, es decir, el sociolecto valenciano y el castellano (estándar y/o murciano seseante). El seseo es una regla variable de la gramática social de la comunidad de habla alicantina, que muestra la estratificación socioeconómica de los hablantes y/o la diferenciación funcional. Aunque tal propuesta merece una ulterior ratificación empirica.

La gramática social sincrónica de nuestra comunidad es multilectal, puesto que se basa en una covariación entre los dos (sub)sistemas de un único repertorio. Descriptivamente, la situación del lecto valenciano más meridional y del murciano seseante responden a variedades intermedias o "gramáticas de transición» - dependiendo del contexto social-, como casos particulares de "gramáticas variacionales», a saber:

a) valenciano-alicantina, que posee una competencia activa del sociolecto valenciano, $y$

b) murciano-alicantina, que tiene una competencia pasiva del sociolecto valenciano.

Cada una de estas gramáticas caracteriza la variedad situada en cierto punto del proceso de sustitución lingüística, y muestra le distancia - mayor o menor, respectivamente - del lecto valenciano al estándar castellano.

La adición de la regla variable del seseo valenciano representa la limitación del cambio cualitativo a cuantitativo en la comunidad de habla alicantina, y tiene lugar mediante una revisión constante y regular de la gramática multilectal de las sucesivas generaciones de hablantes, a través de la sustitución de una competencia activa en pasiva. 
4.2. La dirección del cambio natural va del miembro más marcado (en nuestro caso, regla de interdentalización) hacia el menos marcado (seseo ápico-alveolar valenciano), y ha tenido como resultado un «cambio de norma» histórico de marcado hacia no marcado en el pasado. Sin embargo, esta dirección parece desecharse actualmente, en virtud de la situación diglósica de marginación social y funcional de los lectos alicantinos (valenciano-alicantino $\mathrm{y} / 0$ murciano-alicantino), e implica cambios de no marcado a marcado, invirtiéndose la dirección del cambio natural. Además deben tenerse en cuenta la conciencia lingüística adversa, las formas estigmatizadas del seseo y las actitudes lingüisticas negativas, como manifestaciones de las dimensiones subjetivas del mecanismo del cambio lingüístico en curso.

En suma, la hipótesis puede formularse en los siguientes términos: el seseo valenciano de la comunidad de habla alicantina está en función del grupo socioeconómico bajo y medio-bajo, y afecta generalmente más a los hombres que a las mujeres, y más a los adultos que a los jóvenes. La regla de interdentalización surge en los registros más formales del grupo medio-medio, y se relaciona con los hablantes de mayor ascendiente socioeconómico y con los sectores más jóvenes.

\section{REFERENCIAS BIBLIOGRÄFICAS}

\section{ALARCOS, E.}

1958. "Algunas consideraciones sobre la evolución del consonantismo catalán", in Catalán, D. (ed.), Estructuralismo e historia, Miscelánea homenaje a A. Martinet, II, Universidad de La Laguna, págs. 5-40.

ALONSO, A.

1951. "Origenes del ceceo y del seseo españoles», Thesaurus, 7 (1951), págs. 111-250. Reed. en De la pronunciación medieval a la moderna en español, II, Madrid: Gredos, 1969, págs. 47-144.

1955/1969. De la pronunciación medieval a la moderna en español. Ultimado y dispuesto para la imprenta por R. Lapesa, I (2 edn., Madrid: Gredos, 1967), II (Madrid, 1969), III (en preparación). 
ALVAR, $M$.

1974. "A vueltas con el seseo y el ceceo», Románica, V, págs. 41-57.

BADIA MARGARIT, A.

1951. Gramática histórice catalana, Barcelona: Noguer.

1960. "L'articulació de la $C^{\prime}$ en català primitiu i la seva acció en el procés $C E^{\prime}-C^{\prime} l^{\prime}$.

Complement a una llei fonética observada fa poc temps», Estudis Romànics, VII (1959-1960) págs. 1-9.

1964a. "Català i castellà", in Llengue i culture als Paijos Catalans, 34 edn., Barcelona: Edicions 62, 1972, págs. 63-75.

1964b. "Notes sobre el castellà parlat per catalans", in Llengua i cultura als Països Catalans, 3" edn., Barcelona: Edicions 62, 1972, págs. 149-57.

1965. "Problemes de la commutació consonàntica en català", Boletim de Filologia, XXI, págs. 213-335.

1981. La formació de la llengua catalana. Assaig d'interpretació historica, Barcelona: Publicacions de l'Abadia de Montserrat.

BARNIS GIOL, P.

1913. Die Mundart von Alacant. Beitrag zur Kenntnis dels Valencianischen, Biblioteca Filologica de l'Institut de la Llengua Catalana, Barcelona.

CATALAN, D.

1957a. "El çeçeo-zezeo al comenzar la expansión atlántica de Castilla», Boletim de Filologia, XVI (1956-1957), págs. 305-34.

1957b. "The End of the Phoneme /z/ in Spanish», Word, 13, págs. 283-322.

1958. "Génesis del espaifol atlántico (Ondas varias a través del Océano)", Revista de Historia Canaria (La Laguna), 24, págs. 233-42.

CAVANILLES, A.J.

1795/1797. Observaciones sobre la Historio Natural, Geografla, Agricultura, Población y Frutos del Reyno de Valencia, 2 vols., Valencia, 1972.

\section{CEDERGREN, H. Y D. SANKOFF}

1974. "Variable Rules: Performance as a Statistical Reflection of Competence», Language, 60, págs. 333-55.

ESTAL, J.M. del

1982. Conquista y anexión de las tierras de Alicante, Elche, Orihuela y Guardamar al Reino de Valencia por Jaime // de Aragón (1296-1308), Alicante: Caja de Ahurros Provincial.

FERRANDO FRANCÉS, A.

1980. Consciència idiomática i nacional dels valencians, València: Universitat de València.

FIGUERAS PACHECO, F.

1922. "Provincia de Alicante», in Carreras, F., Geograffa General del Reino de Valencia, tom. IV, Barcelona: A. Martín, 1920-1927.

FUSTER, J.

1962. Nosaltres els valencians, 2 edn., Barcelona: Edicions 62, 1964. 
GALMÉS, A.

1962. Las sibilantes en la Romania, Madrid: Gredos.

GARCIA SORIANO, J.

1932. Vocabulario del dialecto murciano, 2" edn., Murcia: Editora Regional, 1980.

GIMENO, F.

1971. Estudio filológico de la versión romance de Privilegios de Affonso X el Sabio a Alicante, Alicante: Caja de Ahorros Provincial.

1979. "Sociolingüística: Un modelo teórico», Boletín de la Academia Puertorriqueña de ta Lengua Española, 7, 1, págs. 125-68.

1981. "Dimensiones del multilingüismo», Revista Española de Lingü/stica, 11, 2, págs. $341-73$.

1982a. "Alternatives al bilingüisme valencià meridional: A propòsit d'una pre-enquesta sobre les actituds lingüistiques», Treballs de Sociolingülstica Catalana, 4, págs. 51-61.

1982b. "Aproximación sociolingüistica a la comunidad de habla valenciana meridional», in Ninyoles, R. LI. (ed.), Estructura social al Pals. Valencià, Valencia: Diputación Provincial, págs. 725-37.

1983a: "Hacia una sociolinguística histórica", Anales de la Universidad de Alicante. Lingülstica, 1 (en prensa).

1983b. "Die Mundart von Alacant i el bilingüisme alacanti de l'àrea Alacentí-Vinalopón, Actes del / Congrés d'Estudis del Camp d'Alacant, Alicante, 29 de marzo-2 de abril de 1982 (en prensa).

1984a. "A propósito de comunidad de habla: "The Social Dimension of Dialectology» de J.P. Rona", Actas del / Congreso Internacional sobre el español de América, San Juan, 4-9 de octubre de 1982 (en prensa).

1984b. "El sustrato lingüistico y el seseo valenciano de la comunidad de habla alicantinay, Cuadernos de Filologla (Homenaje a M. Sanchis Guarner), 3 (en prensa).

s.f. "Sociolingüística del multilingüismo", Actas del XVI Congreso Internacional de Lingüistica y Filologia Románicas, Palma de Mallorca, 7-12 de abril de 1980 (en prensa).

GUILLÉN, J.

1974. El habla de Orihuela, Alicante: Diputación Provincial.

HADWIGER, $J$.

1905. "Sprachgrenzen und Grenzmundarten des Valencianischen», Zeitschrift für romanische Philologie, XXIX, págs. 712-31.

JAKOBSON, R.

1931. "Prinzipien der historischen Phonologie», TCLP, IV, págs. 247-67. Ref. y trad. fr. "Principes de phonologie historique", in Troubetzkoy, N.S., Principes de phonologie, Apéndice 1, Paris: Éditions Klincksieck, 1964, págs. 315-36.

LABOV, $W$.

1970. "The Study of Language in Its Social Context", in Sociolinguistic Patterns, Oxford: B. Blackwell, 1978, págs. 183-259.

\section{LAPESA, $R$.}

1942/1980. Historia de la lengua española, $8^{\circ}$ edn. ref. y muy aum., Madrid: Gredos. 1957. "Sobre el ceceo y el seseo andaluces», in Catalán, D. (ed.), Estructuralismo e historia, Miscelánea homenaje a A. Martinet, I, Universidad de La Laguna, págs. 67-94. 
1964. «El andaluz y el español de América», in Presente y Futuro de la Lengua Española, II, Madrid: OFINES, págs. 173-82.

LOPEZ GOMEZ, A. Y V.M. ROSELLÓ (dirs.)

1978. Geografia de la provincia de Alicante, Alicante: Diputación Provincial.

LOPEZ MORALES, $\mathrm{H}$.

1981. «Estudio de la competencia sociolingüística: los modelos probabilísticos», Revista Española de Lingüistica, 11,2, págs. 247-68.

LLOBREGAT, E.

1972. Contestania Ibérica, Alicante: Diputación Provincial.

LLUCH, E. (dir.)

1970. L'estructura económica del País Valencià, 2 vols., València: L'Estel.

MENÉNDEZ PIDAL, R.

1908. «Sobre los límites del valenciano. A propósito de J. Hadwiger: Sprachgrenzen und Grenzmundarten des Valencianischen, ZRPh, XXIX, págs. 712-731" in Primer Congrés Internacional de la Llengua Catalana (Barcelona, 1906), Barcelona, págs. 340-4. 1962. "Sevilla frente a Madrid. Algunas precisiones sobre el español de América», in Catalán, D. (ed.), Estructuralismo e historia, Miscelánea homenaje a A. Martinet, III, Universidad de La Laguna, págs. 99-165.

MILLÁN, J.

1976. "Aproximació a l'estudi del canvi de la llengua a la comarca d'Oriola», Serra d'Or (Barcelona), 196 (enero), págs. 29-31.

MONTOYA, B.

1981. Confluència de llengües a les Valls del Vinalopó (Un cas de sociolingüistica valenciana), Memoria de Licenciatura, Facultad de Filosofia y Letras, Universidad de Alicante (inédita).

1982. "Los islotes lingüísticos de Aspe y Elda en el Vinalopó Medio", Revista del Instituto de Estudios Alicantinos, 35, págs. 119-34.

MUNOZ GARRIGOS, J.

1977. "Notas para la delimitación de fronteras del dialecto murciano», Murcia, $2^{\circ}$ trimestre, s. pag.

NAVARRO TOMÁS, T., A. M. ESPINOSA y L. RODRIGUEZ-CASTELLANO

1933. "La frontera del andaluz", Revista de Filologla Española, XX, págs. 225-77.

NINYOLES, R. LI.

1972. Idioma y poder social, Madrid: Tecnos.

OTERO, C.P.

1971/1976. Evolución y revolución en romance. Mínima introducción a la fonolog/a, 2 vols., Barcelona: Seix Barral.

PÉREZ CASADO, R. et al.

1980. Pals Valencià. Geografia i historia, València: E. Climent. 
REGLÁ, J.

1968. Aproximació a la Història del País Valencià, $3^{\mathrm{B}}$ edn., València: E. Climent, 1975.

\section{ROUSSEAU, P. Y D. SANKOFF}

1978. "Advances in Variable Rule Methodology", in Sankoff, D. (ed.), Linguistic Variation. Models and Methods, New York: Academic Press, págs. 57-69.

SANCHIS GUARNER, $M$.

1955/1961. "Els parlars romànics anteriors a la Reconquista de València i Mallorca», Actes et Mémoires du VIlème Congrès International de Linguistique Romane (Barcelona, 1953), II, Barcelona, págs. 455-82. Reed. y rev. ampl. Els parlars romànics anteriors a la Reconquista de València i Mallorca, València: Institució Alfons el Magnànim.

1956. «Factores históricos de los dialectos catalanes», Estudios dedicados a Menéndez Pidal, VI, Madrid, págs. 151-86.

1960. La llengua dels valencians, $4^{a}$ edn., València; L'Estel, 1972.

1961. "Límites y demarcaciones históricas del Reino de Valencia», Feriario (Valencia),

25, págs. 1-12. Reed. en Obra Completa. Per una caracterització valenciana, I, València:

E. Climent, 1976, págs. 87-123.

1973. "La frontera lingüistica en las provincias de Alicante y Murcia», Cuadernos de Geografia, 13, págs. 15-29.

1980. Aproximació a la história de la llengua catalana. Creixença iesplendor, Barcelona:

Salvat.

SANKOFF, D. $y$ W. LABOV

1979. "On the Uses of Variable Rules", Language in Society, 8, págs. 189-222.

TORREBLANCA, M.

1976. Estudio del habla de Villena y su comarca, Alicante: Diputación Provincial.

UBIETO, A.

1975. Origenes del Reino de Valencia. Cuestiones cronológicas sobre su reconquista, Valencia.

VENTURA, A.

1974. "Lluita de llengües al Sud del País Valencià i a Múrcia», Serra d'Or, 179 (agosto), págs. 31-4.

ZAMORA VICENTE, A.

1960. Dialectología española, 2a edn., Madrid: Gredos, 1967.

WEINREICH, U.

1953. Languages in Contact. Findings and Problems, $6^{\circ}$ edn., Mouton: The Hague, 1968. Trad. esp. Lenguas en contacto. Descubrimientos y problemas, Venezuela: Ediciones de la Biblioteca de la Universidad Central, 1974.

1957. "On the Description of Phonic Interference», Word, 13, págs. 1-11. 